Article

\title{
Impact of Recloser on Protecting Blind Areas of Distribution Network in the Presence of Distributed Generation
}

\author{
Jalal Sahebkar Farkhani ${ }^{1}$, Arsalan Najafi ${ }^{2, *}$, Mohammad Zareein ${ }^{3}$, Radu Godina ${ }^{4}(\mathcal{D}$ and \\ Eduardo M. G. Rodrigues ${ }^{5, *}$ \\ 1 Department of Electrical and Computer Engineering, University of Birjand, Birjand 97175, \\ South Khorasan Province, Iran; sahebkar.jalal@gmail.com \\ 2 Faculty of Engineering, Sepidan Branch, Islamic Azad University, Sepidan 73611, Iran \\ 3 Department of Engineering, University of Ferdowsi, Mashhad 91779, Iran; mohammadzareein@gmail.com \\ 4 UNIDEMI, Department of Mechanical and Industrial Engineering, Faculty of Science and Technology (FCT), \\ Universidade NOVA de Lisboa, 2829-516 Caparica, Portugal; r.godina@fct.unl.pt \\ 5 Management and Production Technologies of Northern Aveiro-ESAN, Estrada do Cercal 449, \\ Santiago de Riba-Ul, 3720-509 Oliveira de Azeméis, Portugal \\ * Correspondence: arsalan.najafi@iausepidan.ac.ir (A.N.); emgrodrigues@ua.pt (E.M.G.R.)
}

Received: 16 October 2019; Accepted: 19 November 2019; Published: 25 November 2019

\begin{abstract}
The protection relay issues increase with the penetration of distributed generation (DG) units in distribution networks. Blind protection, sympathetic tripping and failure of reclosing are the frequent problems that are created by adding DG to the distribution networks. This research focuses on the impact of reclosers on overcurrent relay blind protection areas with DGs embedded in the distribution network. The protection blinding in overcurrent relays leads to a delay or non-tripping of the relay. The conventional solution for the blinding issue is to increase the sensitivity in the relay settings. The variation of relay settings may cause problems in the distribution network. This paper investigates the effect of reclosers on eliminating blind areas and improves the reliability in the presence of DG. In this way, possible blind points of the case study are detected, and recloser relays are then installed in appropriate locations. The case study is based on realistic data of a distribution network. The DG consists of two generators with a capacity of $4 \mathrm{MW}$. The simulation is performed in DIgSILENT software.
\end{abstract}

Keywords: blind protection areas; protective relay; overcurrent relay; recloser; reliability

\section{Introduction}

Nowadays, there is an increasing demand for high-quality and reliable electrical energy, and consequently, protection systems play a significant role in the improvement of system reliability [1,2] One challenge for integrating different energy resources, such as distributed generation (DG), is designing a proper protection scheme [3]. Adding DG to the distribution network changes the electrical parameters of the power system and affects the relay protection, causing several types of problems in the protection coordination. The presence of DG can cause many challenges, such as protection blind spots, decreased fault levels and false tripping of feeders in the existing protection of distribution networks $[4,5]$. As reinforcement, false tripping of healthy feeders may be resolved by using a directional overcurrent (OC) relay for the circuit breaker [6]. This research concentrates on the blinding problem of $\mathrm{OC}$ relays in the distribution network.

The most feasible solution for protecting blind areas is to implement new relay operation characteristics with lower tripping limits. In many cases, this is possible and is thus a simple and 
efficient way to avoid blinding-related problems. However, some issues may arise when lowering tripping limits:

- Operation during a fault on an adjacent feeder

- Extreme load/generation combinations

- $\quad$ Starting currents of DG units and other rotating devices

The relay protection blinding in distribution networks is described in [7-9]. In [10,11], the authors present some simulation results to demonstrate scenarios in which the problem may occur. The protection blinding areas may cause delayed operation of OC relays, and in the worst situation, they may lead to the non-tripping of the relay $[12,13]$. The fault current seen by an OC relay decreases due to the DG contribution when the DG is located between the fault point and the OC relay. In [14-16], it is estimated that about $80 \%$ to $90 \%$ of faults on overhead distribution systems are temporary. Therefore, it is common practice to automatically reclose the breaker after tripping, while it remains open for a short time of typically 1 to $5 \mathrm{~s}$. In some cases, utilities may reclose up to three times.

Reclosers are a type of important protective devices in electric power systems that detect overcurrent and break the fault current. Most of temporary faults in overhead distribution systems last only from few cycles to a few seconds. Thus, with their "trip and reclose" capability, reclosers can eliminate prolonged outages on distribution systems effectively [17]. In a conventional radial feeder, reclosers are only expected to detect the unidirectional flow of current. Typically, a recloser upstream from the fault location detects the fault current, trips, and goes into a predefined reclosing sequence in order to restore service if the fault is of a temporary nature $[18,19]$. Optimal placement of protection devices and distributed generators in radial feeders is important to ensure power system reliability [20]. Reclosers have two basic functions in distribution systems: reliability and overcurrent protection [4]. Even though the recloser curve is slightly faster than the feeder OC relay curve, when worst-case faults are considered, it is still possible that the feeder relay to issue a trip command before the recloser does [15]. Therefore, reclosers can improve the reliability of distribution networks. Previously, interruptions shorter than a few minutes were not considered as a source of concerns to most of the customers [21,22]. Most of the protective schemes used for radial distribution systems involve the coordination of fuses, reclosers and overcurrent relays [23,24]. Optimal settings of a recloser involve some parameters with random nature such as fault location, fault type, fault resistance and fault nature (temporary or permanent) [22].

The previous reports have focused more on the problems that are created by adding DG to the distribution networks, such as blind protection, sympathetic tripping and failure of reclosing $[4,5,7,8]$. In $[10,12,22,24-27]$, the recloser settings and coordination with the other protective devices such as fuses and overcurrent relays were studied. The researchers in one study [14] replaced a new solid dielectric with hydraulic reclosers and showed the benefits of this replacement. Another study [15] introduced the development of an analytical mathematical model to describe the fast dynamic response of opening and closing mechanisms of a power line recloser switch. This paper investigates the impact of reclosers on blinding areas of OC relays with DG penetration and fault impedance in a realistic distribution network data. The proposed investigation shows that using a recloser eliminates the blind areas and improves the reliability. In this way, the blind areas of the case study are detected, and then, reclosers are installed in suitable places. The limitation of the blind areas is determined by overcurrent pickup. The effect of the DG and fault impedance are studied on DGs, feeder and recloser relays. The research data is based on a real-time simulation, actual protection relays and real feeders of a distribution network; this enhances the credibility and validity of the reported findings. Overall, the main contributions of the paper are summarized as follows:

- Detecting the fault in blinding areas in the presence of DG and fault impedance.

- Investigating the effect of DG and fault impedance on DGs, feeder and recloser relays.

- Investigating the effect of recloser on protection system and reliability. 
Section 2 presents the blind areas of an OC relay in the distribution network. The settings of the protective relay, simulation results and reliability of the case study are described in Section 3. Moreover, in this section, the blind points that may occur in the case study are explained.

\section{Materials and Methods}

Traditional distribution systems have only one source that contributes to a fault, i.e., the main substation and protective relays are set to see a certain distance down the radial feeder; the minimum fault current that the protective relay can detect decreases over this distance [28]. Phase-to-phase faults with fault point impedance and arc faults are normally suitable for studies as the smallest fault current dictates the operation of the protection system. Phase short-circuit and arc faults have the minimum fault currents, and they may cause more blind areas than other faults [11]. In this study, a phase-to-phase fault is used to investigate the blind areas protection. The probabilities of single phase-to-ground, double phase-to-ground, phase-to-phase and three-phase faults are $80 \%, 17 \%, 2 \%$ and $1 \%$, respectively $[29,30]$.

Of course, the fault point impedance further reduces the minimum fault current. Faults with different impedances have been used in many papers. In [21,31], various fault resistances were considered from 0 (solid fault) to $100 \mathrm{ohms}$. Blind areas in OC relays may cause delay in the operation of relays and can potentially lead to the non-tripping of the relays in the worst situation. A blind spot is more possible when DG is installed between the fault point and the feeding substation. The presence of DG decreases the fault current seen by the relay at the same time. The effect of DG on power system depends on the location, type and size of the installed DG. However, the fault current in the feeder relay decreases due to the DG contribution. This happens when the total current is divided among the feeding sources. The protection may become inoperative in the worst-case faults, thus, it should be adjusted before the presence of DG [32].

Figure 1 shows the blinding points with DG in a simple diagram of the case study. The three blinding points are the candidate points in the case study, which include Point 1 (the end of the main feeder), Point 2 (the beginning of the adjacent feeder when circuit breaker (CB) ring is closed and both feeders are fed by the main feeder) and Point 3 (local load). In this case, we have three blind points that need two recloser relays; R1 (location of recloser 1) and R2 (location of recloser 2) are the suitable locations for the reclosers as shown in the figure. This study considers only relay R1.

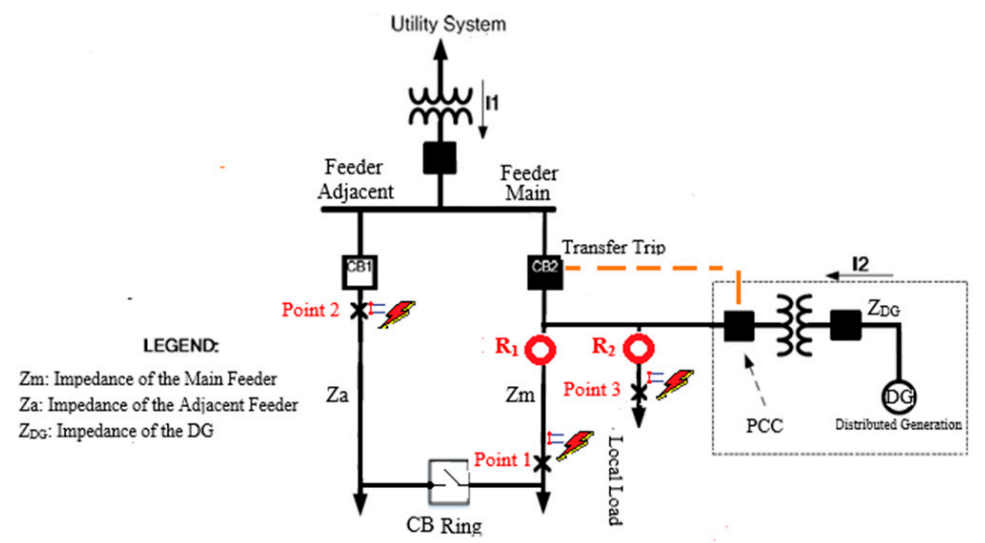

Figure 1. Possible blinding points in the case study. PCC: Point of Common Coupling CB: Circuit Breaker.

In case of a fault at the end of the feeder, the fault current is supplied from both the utility network (I1) and DG (I2). The fault current from the utility network is reduced because of the contribution of the local generation. If the local feeder protection settings are not adjusted to incorporate DG, the relay may not see the fault and will not operate [25]. 
Traditionally, DGs are not operated in islanded mode, and the generators need to be disconnected from the system. The remote transfer trip opens the circuit breaker of the DG in case of a fault on the feeder.

The worst situation for the relay in a blind area is its inability to operate in case of fault occurrence. The relay operation depends on pickup current. When the relay cannot pick up as a short-circuit fault occurs, the relay setting is under blinding point. The three-phase short-circuit current at any point within the power system is obtained as follows:

$$
I_{S C}=\frac{U}{\sqrt{3} \times Z_{S C}}
$$

where $U$ refers to the phase-to-phase voltage at the fault location before fault occurrence, and $Z_{S C}$ is the equivalent upstream power system impedance seen at the fault point.

The blind points occur when the short-circuit current $\left(I_{S C}\right)$ value is less than the relay pickup current. In the case study, the pickup current of the main feeder is calculated as: $I_{\text {Pickup }}=1 \times I_{n}=400 \mathrm{~A}$. Therefore, the relay is in the blind areas when the short-circuit current is less than the pick-up current:

$$
I_{S C} \leq 400 A
$$

Therefore, the maximum impedance that causes the blind point is as follows:

$$
Z_{\text {Blind }}=\frac{U}{\sqrt{3 \times I_{S c}}}
$$

Parameter $Z_{\text {Blind }}$ depends on the fault point voltage and short-circuit current. It is well known that the voltage profile of a radial feeder decreases from the utility substation to the end of the feeder [33,34].

Table 1 shows the path impedances at each fault point. According to the single diagram of the case study in Figure 1, the figure shows the distance from each power source to fault points (1-3). The parameters of path lengths and impedances are given in Table A2 of the Appendix A. The maximum path impedance of the fault points is related to point 3 because of feeder length.

Table 1. Path impedances of fault points without fault impedance. DG: distributed generation.

\begin{tabular}{cccc}
\hline Impedance & Point $\mathbf{1}$ & Point $\mathbf{2}$ & Point $\mathbf{3}$ \\
\hline DG & $0.523 \Omega$ & $1.089 \Omega$ & $8.463 \Omega$ \\
Feeder & $1.077 \Omega$ & $1.65 \Omega$ & $9.27 \Omega$ \\
\hline
\end{tabular}

\section{Results}

\subsection{Case Study}

The case study in this research is based on a real power system. The power system includes two $20 \mathrm{KV}$ feeders, which are called the main feeder and adjacent feeder. The DG is embedded on the main feeder, and the adjacent feeder can be fed by the main feeder. Figure 2 depicts the topology of the case study consisting of the two feeders. The length of the main feeder is $3.64 \mathrm{~km}$, and it has more energy consumption due to an industrial area. The maximum current of the main feeder is about 102 A. Moreover, the adjacent feeder has a longer length $(26.76 \mathrm{~km})$ with residential loads. The maximum current of the adjacent feeder has been recorded $73 \mathrm{~A}$. The main feeder consumes more energy, while the adjacent feeder line is much longer. The DG is connected to the substation by the feeders. According to Equation (3), an impedance more than $28.85 \Omega$ causes blind areas, and the three-phase short-circuit current is around $12.5 \mathrm{kA}$. There are two $132 / 20 \mathrm{kV}$ transformers rated at $30 \mathrm{MVA}$ in the substation. The simulations are conducted in DIGSILENT software (version 15.1, DIgSILENT GmbH, Gomaringen, Germany, 2016) [35]. 


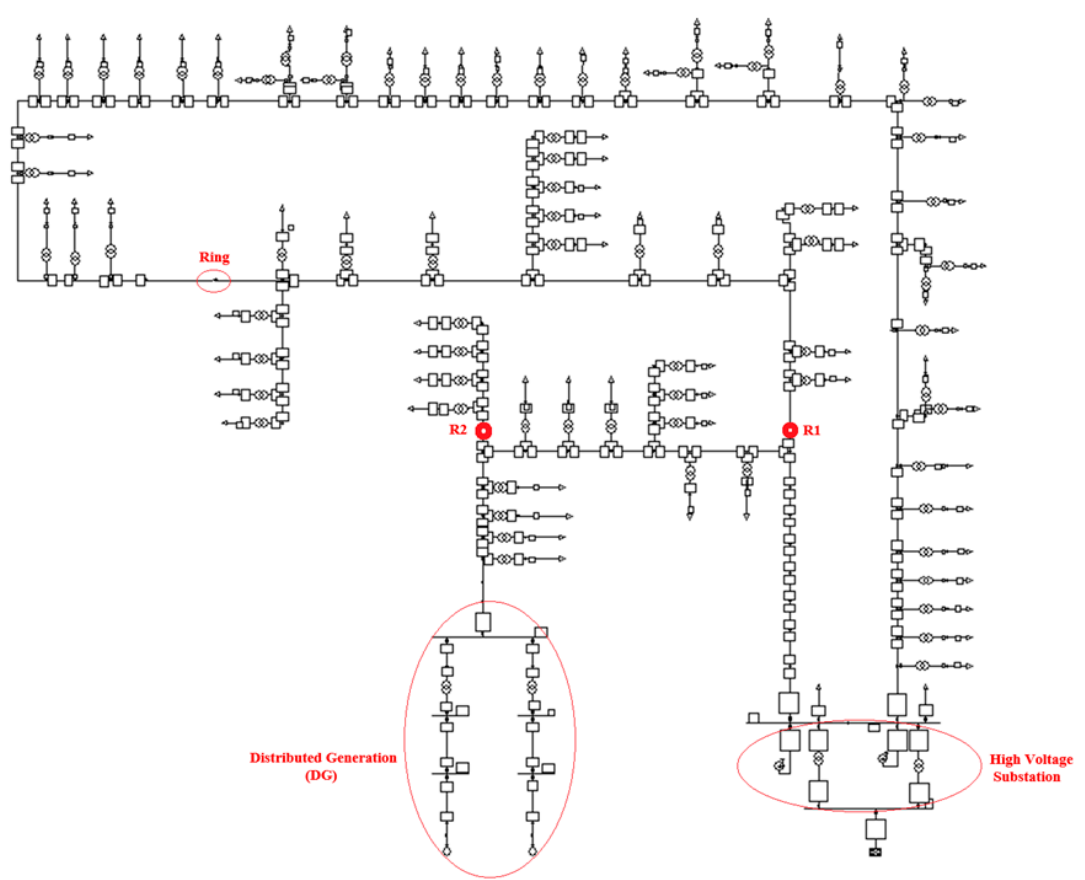

Figure 2. Single diagram of real distribution network with DG.

\subsection{Settings of Protective Devices}

The most common protection devices used in distribution systems are OC relays. The OC relays are used as the main protection devices for radial distribution systems [30]. An OC relay measures the current flowing through it and determines whether to send a signal to open a circuit breaker $[26,36]$.

An OC relay trip settings are determined by "pickup current (Ip)" and "time delay" parameters. Pickup current is the threshold current value and is sensed by current level detection principle, which has to be exceeded for relay trip [27].

The pickup current of an OC relay is set in such a manner that it is larger than the rated current of the feeder but less than the minimum short-circuit current of the protected zone. When the DG unit and the substation are feeding the fault in parallel, the fault current detected by the OC relay is reduced (due to the contribution of DG to the fault current). This causes the relay to under reach its required protective zone. In other words, the relay is "blind" to the fault $[37,38]$.

In distribution feeder protection, the most important variable in optimal coordination of OC relays is the time multiplier setting (TMS). The operating time of a relay is a function of TMS, Ip and short-circuit current seen by the relay. The operating time of relay is given by Equation (4):

$$
t_{o p}=\frac{\alpha \times T M S}{\left(\frac{I_{f}}{I_{P}}\right)^{\beta}-\gamma}
$$

where $\alpha, \beta$ and $\gamma$ are constants that are used to represent a mathematical form of an inverse-definite minimum time (IDMT) type of OC relay characteristic. The values of $0.14,0.02$ and 1.0 are, respectively, set for $\alpha, \beta$ and $\gamma$ to define an IDMT OC relay. Similarly, the recloser relay also has an inverse-time OC characteristic [39].

In this section, the OC relay settings of the DG and substation feeder are presented, and the recloser relay settings is then adjusted. The calculation of DG protective relay at Point of Common Coupling (PCC) is based on the generator transient stability. The overcurrent relay time constraint settings of generators for three-phase faults should be under $0.35 \mathrm{~s}$ [40]. The OC pickup of the relay is:

$$
\text { P.S }=1.2 \times I_{n}=141 \times 1.2=170 A
$$


The formulation of relay operating time with normally inverse characteristic is given by Equation (4) $(\alpha=0.14, \beta=0.02)$ :

$$
t=\frac{0.14}{\left(\left(\frac{I_{f}}{I_{P}}\right)^{0.02}-1\right)} \times \mathrm{TMS}
$$

The TMS of an overcurrent relay of DG is calculated as follows:

$$
T M S=\frac{0.35 \times\left(\left(\frac{1686}{170}\right)^{0.02}-1\right)}{0.14}=0.117 \approx 0.12
$$

Table 2 provides the protective relay settings of DG at the PCC point.

Table 2. Overcurrent relay settings of DG. OC: overcurrent; TMS: time multiplier setting

\begin{tabular}{ccccccc}
\hline OC Settings & $\begin{array}{c}\text { Current } \\
\text { Transformer }(C T) \\
\text { ratio }\end{array}$ & $\begin{array}{c}\text { Pickup Current } \\
\left(I_{\text {Pickup }}\right)(A)\end{array}$ & Curve & $\begin{array}{c}\text { Fault } \\
\text { Current }\left(I_{\mathrm{f}}\right) \\
(\mathbf{k A})\end{array}$ & TMS & $\begin{array}{c}\text { Instantaneous } \\
\text { Current }\end{array}$ \\
\cline { 2 - 6 } & $200 / 1$ & $0.85^{*} \mathrm{In}$ & N.I & 8.89 & 0.12 & $10^{*}$ In \\
\hline
\end{tabular}

In addition, the settings of the $20 \mathrm{kV}$ feeder does not change and is fixed. The relay settings of the substation $20 \mathrm{kV}$ feeder are presented in Table 3.

Table 3. Relay settings of the substation $20 \mathrm{kV}$ feeder.

\begin{tabular}{ccccccc}
\hline \multirow{2}{*}{ OC Settings } & CT & $\boldsymbol{I}_{\text {Pickup (A) }}$ & Curve & $\boldsymbol{I}_{\mathrm{f}}$ (KA) & TMS & $\begin{array}{c}\text { Instantaneous } \\
\text { Current }\end{array}$ \\
\cline { 2 - 7 } & $400 / 1$ & $1 *$ In & N.I & 12.5 & 0.1 & $10^{*} \mathrm{In}$ \\
\hline
\end{tabular}

Connecting DG to the distribution network boosts the severity of short-circuit. In the case study, the short-circuit current increases to $14.31 \mathrm{kA}$ after connecting DG to the main feeder.

The recloser relay settings should be set to avoid blind areas. Therefore, the recloser should operate faster than the OC relay. The pickup current of the recloser relay is around twice the maximum feeder current. Figure 3 shows the substation OC and recloser relays characteristic curves in DIgSILENT.

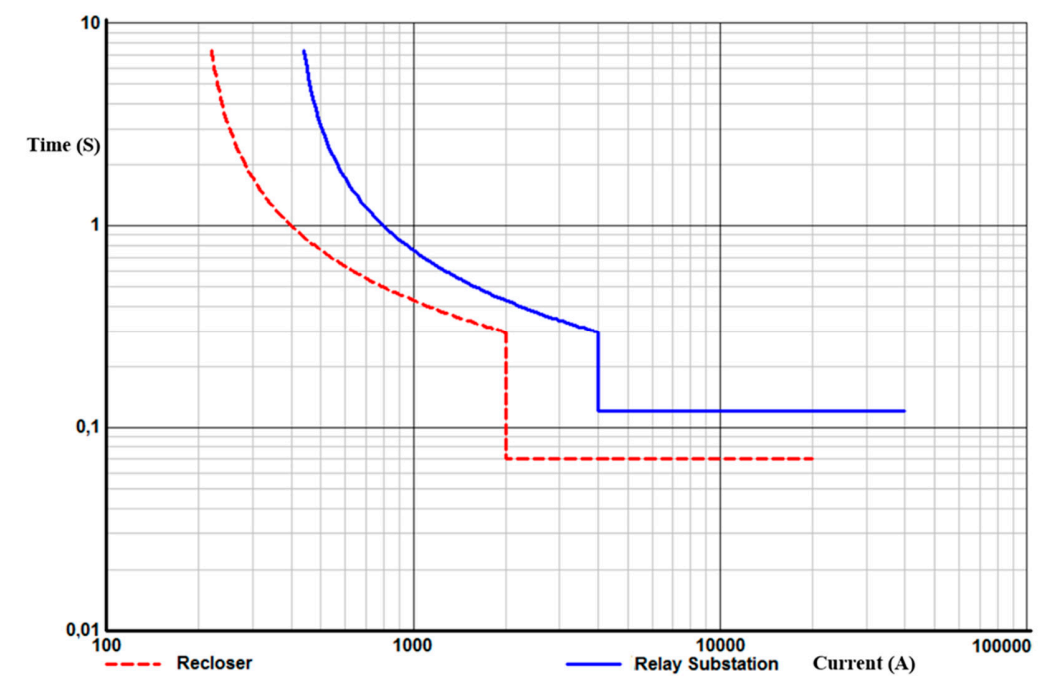

Figure 3. Comparison of overcurrent relay characteristic curves of substation $20 \mathrm{kV}$ feeder and recloser relays. 


\subsection{Discussion}

In this subsection, the effect of fault impedance on the protection blinding areas for phase-to-phase faults is studied. In fact, protection blinding causes non-operation or delay in the OC relay. The priority of the research is to avoid blind areas, and the secondary goal is to improve the reliability of the power system.

Figures 4 and 5 show the operating times of overcurrent recloser and DG relays with different fault impedances at points 1 and 2. The short-circuit current value decreases by increasing the fault impedance that, in turn, causes an increase in the operating time of the protective relay. The length of the feeder (line impedance) is also effective. Line length at point 2 is more than the line length at point 1. Therefore, considering a fault with the same fault impedance, the relay operating time at point 2 is more than that at point 1 . The main feeder relay cannot operate in case of a fault impedance of more than $40 \Omega$ at point 1 and $20 \Omega$ at point 2 . The relay of DG detects faults just with $Z=0$ ohms at point 1 and cannot detect a fault at point 2 . The recloser relay can detect any fault with various impedances.

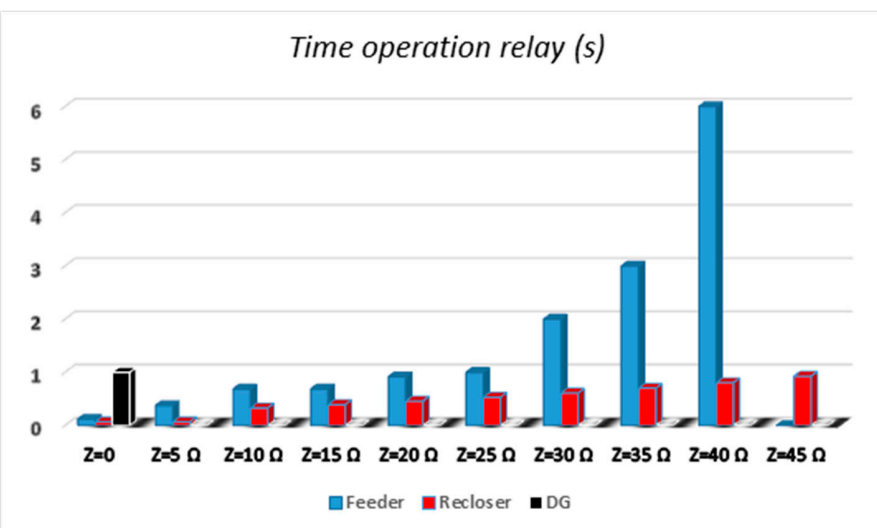

Figure 4. Operating times of overcurrent, recloser and DG relays with different fault impedances at point 1.

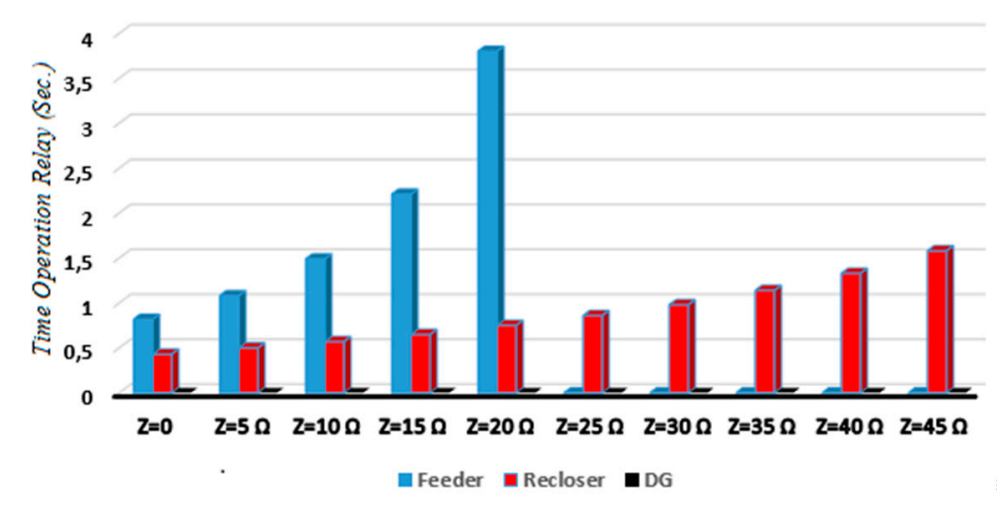

Figure 5. Operating times of overcurrent, recloser and DG relays with different fault impedances at point 2.

The operating time of the main feeder relay gradually increases with an increase in the fault impedance at point 1 . The main feeder relay operating time is around $6 \mathrm{~s}$ for a fault impedance of $40 \Omega$ (Figure 4). The main feeder relay cannot detect a fault with an impedance of $45 \mathrm{ohms}$. The operating time of the DG relay is around $1 \mathrm{~s}$ with zero fault impedance, while it does not operate when the fault has impedance. In addition, the recloser relay can detect faults with $45 \mathrm{ohms}$ impedance in less than $1 \mathrm{~s}$.

The DG relay does not operate with a fault at point 2 . The operating time of the main feeder relay is about $4 \mathrm{~s}$ at $\mathrm{Z}=20 \mathrm{ohms}$. 
Table 4 lists the operating times of the main feeder, DG and recloser relays with different fault impedances. In the table, the blind areas in the case study are indicated with Non (non-operation). The relay operating times are obtained by changing the fault impedance at points 1 and 2 . The locations of the relays are shown in Figure 2. The feeder and DGs relays cannot detect the fault by increasing the fault impedance, while the recloser relay can detect.

Table 4. Relay operating times with different fault point impedances.

\begin{tabular}{ccccccc}
\hline \multirow{2}{*}{$\begin{array}{c}\text { Fault } \\
\text { Impedance } \\
\text { (ohm) }\end{array}$} & \multicolumn{7}{c}{ Relay Operating Time (s) } \\
\cline { 2 - 6 } & Feeder & DG & Recloser & Feeder & DG & Recloser \\
\cline { 2 - 6 } & Point 1 & 0.818 & Non & 0.434 \\
$Z=0$ & 0.12 & 1.046 & 0.07 & 1.086 & Non & 0.5 \\
$Z=5 \Omega$ & 0.376 & Non & 0.07 & 1.497 & Non & 0.573 \\
$Z=10 \Omega$ & 0.515 & Non & 0.329 & 2.216 & Non & 0.656 \\
$Z=15 \Omega$ & 0.687 & Non & 0.393 & 3.814 & Non & 0.75 \\
$Z=20 \Omega$ & 0.917 & Non & 0.46 & Non & Non & 0.86 \\
$Z=25 \Omega$ & 1.251 & Non & 0.532 & Non & Non & 0.989 \\
$Z=30 \Omega$ & 1.792 & Non & 0.612 & Non & Non & 1.146 \\
$Z=35 \Omega$ & 2.844 & Non & 0.703 & Non & Non & 1.338 \\
$Z=40 \Omega$ & 5.828 & Non & 0.806 & Non & Non & 1.584 \\
$Z=45 \Omega$ & Non & Non & 0.927 & & & \\
\hline
\end{tabular}

Figures 6 and 7 show the main feeder and recloser relays with a fault impedance of $25 \Omega$ at points 1 and 2, respectively. The operating time of the main feeder relay is around twice that of the recloser relay for a fault at point 1 . The recloser and OC relays operate around $530 \mathrm{~ms}$ and $1.25 \mathrm{~s}$, respectively.

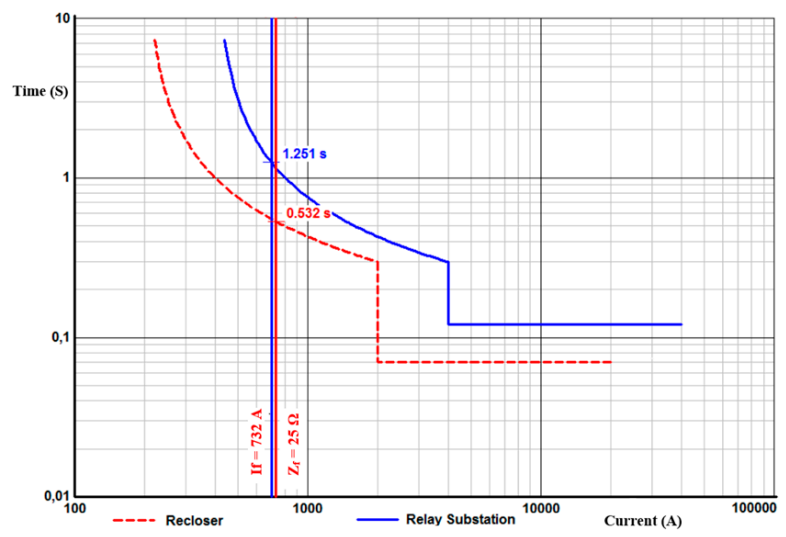

Figure 6. Operating time of overcurrent and recloser relays with fault impedance $25 \Omega$ at point 1 .

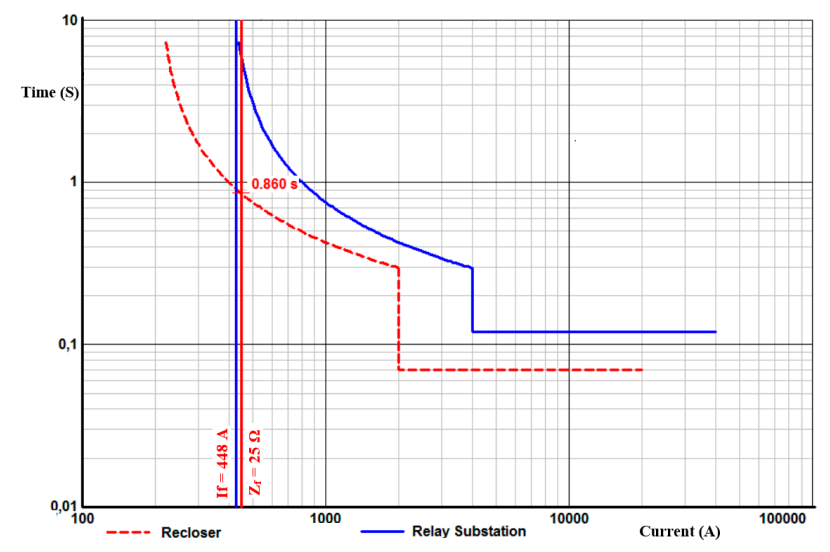

Figure 7. Operating time of overcurrent and recloser relays with fault impedance $25 \Omega$ at point 2 . 
The main feeder relay does not operate with a fault impedance of $25 \mathrm{ohms}$ at point 2 , while the operating time of the recloser is $860 \mathrm{~ms}$.

\subsection{Reliability}

Since a typical distribution system accounts for $40 \%$ of the cost to deliver power and $80 \%$ of customer reliability problems, the designing and operating of distribution systems are critical for financial success of a utility company and customer satisfaction. The reliability improvement can be obtained in term of the reduction of outage duration. Figure 8 shows the cost versus system reliability [41].

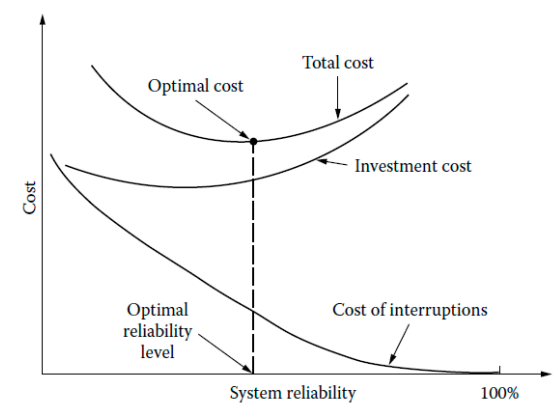

Figure 8. Cost versus system reliability [42].

Interruptions and outages can be studied using predictive reliability assessment tools that can predict customer reliability characteristics based on system topology and component reliability data. In order to achieve this, distribution reliability indices are calculated. Such reliability indices should be concerned with both duration and frequency of outage [42].

The reliability of the case study is calculated by the FMEA (Failure mode and effect analysis) method. The recloser reduces the outages and improves the reliability.

The method FMEA is based on the maintenance philosophy aimed at failure-free operation and reliability-centered maintenance (RCM). The task of RCM is to perform the analysis in such a way as to minimize the negative effects, and to help solving problems effectively or to prevent them [43].

Table 5 shows the outage rate of the case study feeder in 2018. The total outage of the main feeder is $27.03 \mathrm{~h}$ that includes $15.4 \mathrm{~h}$ of preventive maintenance (PM) over the year.

Table 5. Outage rate of the case study feeder in 2018. PM: preventive maintenance.

\begin{tabular}{|c|c|c|c|c|}
\hline \multirow{2}{*}{ Year } & \multirow{2}{*}{ Cause } & \multicolumn{2}{|c|}{ Number } & \multirow{2}{*}{ FOR hrs/yr } \\
\hline & & Total & Outages & \\
\hline \multirow{4}{*}{2018} & PM & 2 & 2 & 15.4 \\
\hline & Relay Operation & 22 & 2 & 0.31 \\
\hline & Other Outages & 4 & 4 & 11.32 \\
\hline & \multicolumn{3}{|c|}{ Total Outages (hours) } & 27.03 \\
\hline
\end{tabular}

The recloser location is suggested to be at the half-way point of the radial feeder, assuming a uniformly distributed load. This would yield a $50 \%$ reliability improvement to customers upstream from the recloser. Similarly, locations at $1 / 3$ and $2 / 3$ of the feeder length should be considered if two reclosers are placed [19]. Figure 9 shows two sections with recloser relay. In case of a fault on the feeder in section $B$, the recloser relay operates and disconnects the faulty section from the healthy part. Therefore, the customers in section B and DG will remain in the power system. However, without the recloser relay, a fault on the feeder will disconnect the customers and DG from rest of the power system. 


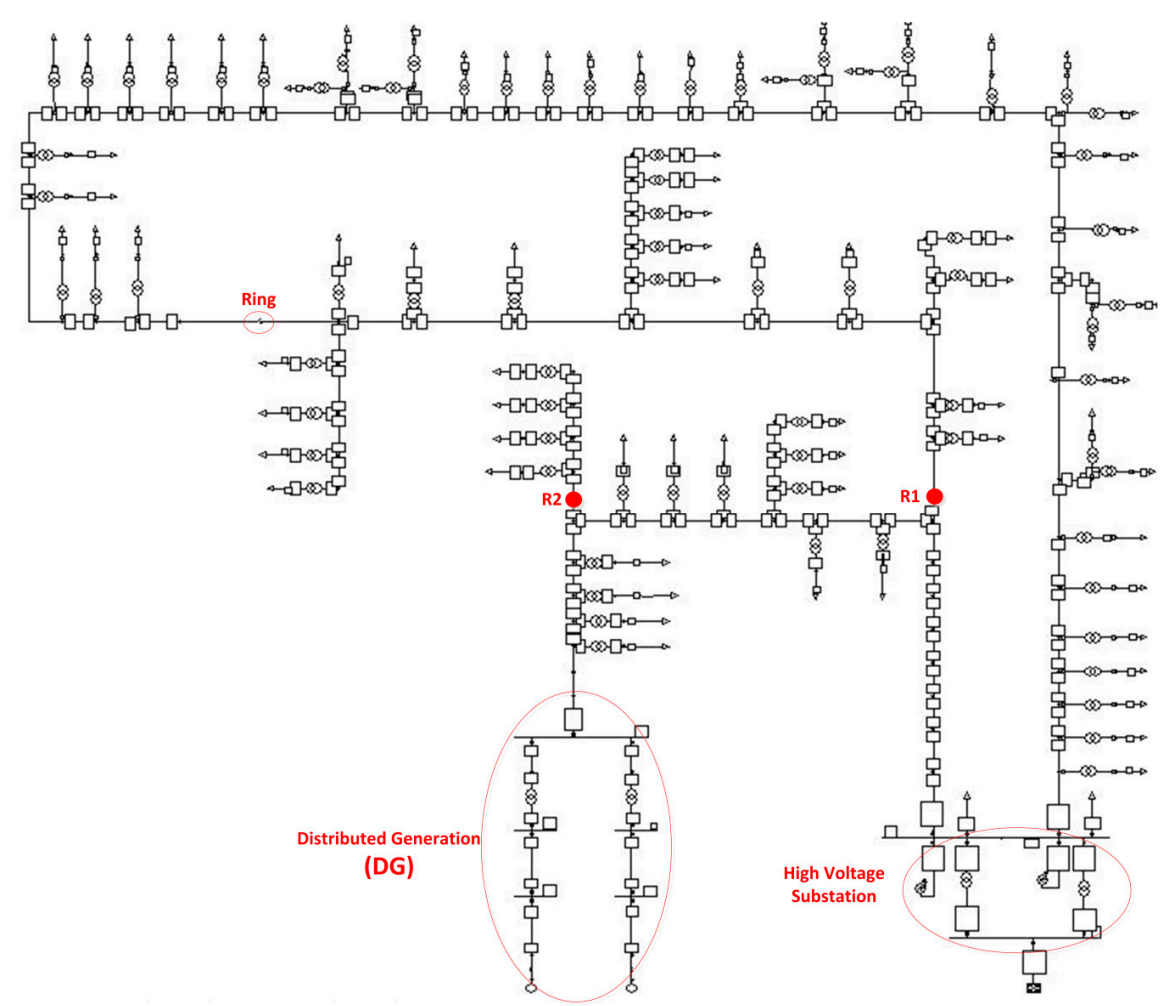

Figure 9. Reliability sections of the case study.

The failure parameters of the case study are as follows:

$$
\begin{array}{ll}
\lambda_{A}=2.8 & r_{A}=3 \\
\lambda_{B}=1.7 & r_{B}=2
\end{array}
$$

where $\lambda$ is the failure rate on the feeder, and $r$ is the failure duration of the feeder.

Considering outage times except for PM times, the average duration of outages of the feeder is obtained:

$$
r_{A}=\frac{\sum_{m=1}^{n}\left(\lambda_{m} \times r_{m}\right)}{\sum_{m=1}^{n} \lambda_{m}}=\frac{2.8 \times 3+1.7 \times 2}{4.5}=2.62=r_{B}
$$

For the whole feeder, the result is the same.

After installing the relay within $0.4 \mathrm{~h}$, the operation averages of outages in A and B paths are presented as follows:

$$
\begin{gathered}
r_{A}=\frac{\sum_{m=1}^{n}\left(\lambda_{m} \times r_{m}\right)}{\sum_{m=1}^{n} \lambda_{m}}=\frac{2.8 \times 0.4+2.2 \times 3}{4.5}=1.71 \\
r_{B}=\frac{\sum_{m=1}^{n}\left(\lambda_{m} \times r_{m}\right)}{\sum_{m=1}^{n} \lambda_{m}}=\frac{2.8 \times 3+1.7 \times 2}{4.5}=2.62
\end{gathered}
$$

The average duration of power outages (hours) in section A decreases from 2.62 to $1.71 \mathrm{~h}$. 


\section{Conclusions}

This paper studied the impact of recloser in protecting blind areas of a real distribution network with DGs penetration using the DIgSILENT software. Due to the DG contribution in the distribution network, the short-circuit current seen by the OC relay decreases. The blind protection issues may cause non-operation or delay in the OC relay with fault point impedance. The limitation of the fault point impedance is determined by the relay feeder pickup current. Increasing the relay sensitivity is the conventional solution for the protection blind areas. In this paper, a recloser was proposed as a way to avoid blind protection due to adding DG to the distribution network. In this way, the blind areas of the case study were detected and then a recloser was installed in a suitable location.

As the results show, the operating time of the protective relay increases with the fault point impedance. This causes the OC relay goes into a blind area. The recloser curve setting closes faster than the feeder relay curve, so the recloser relay operates faster than the OC relay. Accordingly, the protection blind areas are protected by the recloser relay. The delay in the relay operating time decreases with fault impedance. The recloser improves the reliability of the case study. Moreover, the total outage of the feeder is reduced to around half.

Author Contributions: J.S.F.: Writing and simulating original paper; A.N.: conceptualization, supervision, methodology and revising; M.Z. conceptualization, analyzing data; R.G.: editing, funding acquisition; E.M.G.R.: editing.

Funding: Radu Godina would like to acknowledge financial support from the Fundação para a Ciência e Tecnologia (UID/EMS/00667/2019).

Conflicts of Interest: The authors declare no conflict of interest.

\section{Appendix A}

The specifications of the generator are as follows: nominal power $2500 \mathrm{KVA}$, frequency $50 \mathrm{~Hz}$, nominal voltage $10.5 \mathrm{kV}$ and power factor 0.8 . The generator transient components parameters are provided in Table A1.

Table A1. Generator transient components parameters.

\begin{tabular}{ccc}
\hline Reactance & Ohm & \% \\
\hline $\mathbf{X d}$ & 115.99 & 263 \\
$\mathbf{X q}$ & 63.259 & 143.4 \\
$\mathbf{X d}^{\prime}$ & 11.035 & 25 \\
$\mathbf{X d}^{\prime \prime}$ & 9.148 & 20.7 \\
$\mathbf{X q}^{\prime \prime}$ & 9.874 & 22.4 \\
$\mathbf{X 2}$ & 9.535 & 21.6 \\
$\mathbf{X 0}$ & 1.21 & 2.7 \\
\hline
\end{tabular}

Line parameters are given in Table A2.

Table A2. Line parameters.

\begin{tabular}{ccccc}
\hline Type of Conductor & Voltage (kV) & $\begin{array}{c}\text { Cross-Section } \\
\text { Area }\left(\mathbf{m m}^{2}\right)\end{array}$ & Resistance $(\boldsymbol{\Omega} / \mathbf{k m})$ & Reactance $(\boldsymbol{\Omega} / \mathbf{k m})$ \\
\hline $\operatorname{dog}$ & $20 \mathrm{KV}$ & 118.5 & 0.2791 & 0.102 \\
\hline
\end{tabular}

\section{References}

1. Gers, J.M.; Holmes, E.J. Protection of Electricity Distribution Networks; IET Press: Stevenage, UK, 1998.

2. Dehghanian, P.; Wang, B.; Tasdighi, M. New Protection Schemes in Smarter Power Grids with Higher Penetration of Renewable Energy Systems. In Pathways to a Smarter Power System; Academic Press: Cambridge, MA, USA, 2019; pp. 317-342. [CrossRef] 
3. Manditereza, P.T.; Bansal, R. Renewable distributed generation: The hidden challenges-A review from the protection perspective. Renew. Sustain. Energy Rev. 2016, 58, 1457-1465. [CrossRef]

4. Zayandehroodi, H.; Mohamed, A.; Shareef, H.; Mohammadjafari, M. A Comprehensive review of protection coordination methods in power distribution systems in the presence of DG. Przeglad Elektrotechniczny 2011, $87,142-148$.

5. Javadian, S.A.M.; Haghifam, M.-R.; Fotuhi Firoozabad, M.; Bathaee, S.M.T. Analysis of protection system's risk in distribution networks with DG. Int. J. Electr. Power Energy Syst. 2013, 44, 688-695. [CrossRef]

6. Coffele, F.; Booth, C.; Dyśko, A.; Burt, G. Quantitative analysis of network protection blinding for systems incorporating distributed generation. IET Gener. Transm. Distrib. 2012, 6, 1218-1224. [CrossRef]

7. Shahzad, U.; Kahrobaee, S.; Asgarpoor, S. Protection of Distributed Generation: Challenges and Solutions. Energy Power Eng. 2017, 9, 614. [CrossRef]

8. Papaspiliotopoulos, V.A.; Kleftakis, V.A.; Kotsampopoulos, P.C.; Korres, G.N.; Hatziargyriou, N.D. Hardware-in-the-loop simulation for protection blinding and sympathetic tripping in distribution grids with high penetration of distributed generation. In Proceedings of the MedPower, Athens, Greece, 2-5 November 2014.

9. Dugan, R.C.; McDermott, T.E. Distributed generation. IEEE Ind. Appl. Mag. 2002, 8, 19-25. [CrossRef]

10. Firouz, Y.; Farhadkhani, S.; Lobry, J.; Vallée, F.; Khakpour, A.; Durieux, O. Numerical comparison of the effects of different types of distributed generation units on overcurrent protection systems in MV distribution grids. Renew. Energy 2014, 69, 271-283. [CrossRef]

11. Maki, K.; Repo, S.; Jarventausta, P. Protection coordination to meet the requirements of blinding problems caused by distributed generation. WSEAS Trans. Circuits Syst. 2005, 4, 674.

12. Zohour Attar, M.; Sasani, N. Solutions to Design and Coordination Relays for Protection Challenges of Distribution Network with DG. J. Appl. Environ. Biol. Sci. (JAEBS) 2015, 14, 118-127.

13. Glinka, F. Solutions for blinding of protection in today's and future German LV grids with high inverter penetration-Simulative and experimental analysis. J. Eng. 2018, 2018, 1256-1260. [CrossRef]

14. Wright, L.; Ayers, L. Mitigation of Undesired Operation of Recloser Controls Due to Distribution Line Inrush. In Proceedings of the 2015 IEEE Rural Electric Power Conference, Asheville, NC, USA, 19-21 April 2015.

15. He, L.; Mayor, J.R.; Harley, R.G.; Liles, H.; Zhang, G.; Deng, Y. Multiphysics Modeling of the Dynamic Response of a Vacuum Automatic Circuit Recloser System. IEEE Trans. Ind. Appl. 2014, 50, 3697-3707. [CrossRef]

16. IEEE SA. IEEE Std C 37.60-2012_IEEE/IEC International Standard-High-voltage Switchgear and Control Gear-Part 111: Automatic Circuit Reclosers and Fault Interrupters for Alternating Current Systems up to $38 \mathrm{kV}$; IEEE SA: Piscataway, NJ, USA, 2012.

17. Rhee, S.; Lee, J.; Lee, B. Impacts of superconducting fault current limiters on the recloser operation in distribution electric power systems. IEEE Trans. Appl. Supercond. 2010, 21, 2197-2200. [CrossRef]

18. Bergen, A.R. Power System Analysis, 1st ed.; Prentice-Hall: Memphis, TN, USA, 1986.

19. Dehghani, N.; Dashti, R. Optimization of Recloser Placement to Improve Reliability by Genetic Algorithm. Energy Power Eng. 2011, 3, 508-512. [CrossRef]

20. Wang, L.; Singh, C. Reliability-constrained optimum placement of reclosers and distributed generators in distribution networks using an ant colony system algorithm. IEEE Trans. Syst. Man Cybern. Part C (Appl. Rev.) 2008, 38, 757-764. [CrossRef]

21. Bollen, M.H.J. Understanding Power Quality Problems: Voltage Sags and Interruptions; Wiley-IEEE Press: New York, NY, USA, 2000; ISBN 9780470546840.

22. Azari, N.R.; Chitsazan, M.A.; Niazazari, I. Optimal Recloser Setting, Considering Reliability and Power Quality in Distribution Networks. Am. J. Electr. Power Energy Syst. 2017, 6, 1-6. [CrossRef]

23. Anderson, P.M. Power System Protection; IEEE Press, McGraw-Hill: New York, NY, USA, 1999; pp. $220-224$.

24. Shah, P.H.; Bhalja, B.R. New adaptive digital relaying scheme to tackle recloser-fuse mis-coordination during distributed generation interconnections. IET Gener. Transm. Distrib. 2014, 8, 682-688. [CrossRef]

25. Antonova, G.; Nardi, M.; Scott, A.; Pesin, M. Distributed Generation and Its Impact on Power Grids and Microgrids Protection. In Proceedings of the 2012 65th Annual Conference for Protective Relay Engineers, College Station, TX, USA, 2-5 April 2012. 
26. Alkaran, D.S.; Vatani, M.R.; Sanjari, M.J.; Gharehpetian, G.B.; Yatim, A.H. Overcurrent relays coordination in interconnected networks using accurate analytical method and based on determination of fault critical point. IEEE Trans. Power Deliv. 2015, 30, 870-877. [CrossRef]

27. Ilik, S.C.; Arsoy, A.B. Effects of Distributed Generation on Overcurrent Relay Coordination and an Adaptive Protection Scheme. IOP Conf. Ser. Earth Environ. Sci. 2017, 73, 012026. [CrossRef]

28. Papaspiliotopoulos, V.A.; Korres, G.N.; Hatziargyriou, N. An Adaptive Protection Infrastructure for Modern Distribution Grids with Distributed Generation. Available online: https://pdfs.semanticscholar.org/a6e5/ 1e0cb98cfd5897fa6604be256587b2c9b6b5.pdf (accessed on 24 November 2019).

29. Martinez, J.A.; Martin-Arnedo, J. Voltage Sags Analysis Using an Electromagnetic Transient Program. In Proceedings of the IEEE Power Engineering Society Winter Meeting, New York, NY, USA, 27-31 January 2002; pp. 1135-1140.

30. Beiza, J.; Hosseinian, S.; Vahidi, B. Fault Type Estimation in Power Systems. Iran. J. Electr. Electron. Eng. 2009, 5, 185-195.

31. Sortomme, E.; Venkata, S.; Mitra, J. Microgrid Protection Using Communication-Assisted Digital Relays. IEEE Trans. Power Deliv. 2009, 25, 2789-2796. [CrossRef]

32. Chen, P.-C.; Salcedo, R.; Zhu, Q.; de Leon, F.; Czarkowski, D.; Jiang, Z.-P.; Spitsa, V.; Zabar, Z.; Uosef, R.E. Analysis of Voltage Profile Problems Due to the Penetration of Distributed Generation in Low-Voltage Secondary Distribution Networks. IEEE Trans. Power Deliv. 2012, 27, 2020-2028. [CrossRef]

33. Bokhari, A.; Raza, A.; Diaz-Aguiló, M.; de León, F.; Czarkowski, D.; Uosef, R.E.; Wang, D. Combined Effect of CVR and DG Penetration in the Voltage Profile of Low-Voltage Secondary Distribution Networks. IEEE Trans. Power Deliv. 2015, 31, 286-293. [CrossRef]

34. Balamurugana, K.; Srinivasana, D.; Reindlb, T. Impact of Distributed Generation on Power Distribution Systems. Energy Procedia 2012, 25, 93-100. [CrossRef]

35. DIgSILENT. Power System Software \& Engineering. Available online: https://www.digsilent.de/ (accessed on 24 November 2019).

36. Kiliçkiran, H.C.; Şengör, İ.; Akdemir, H.; Kekezoğlu, B.; Erdinç, O.; Paterakis, N.G. Power system protection with digital overcurrent relays: A review of nonstandard characteristics. Electr. Power Syst. Res. 2018, 164, 89-102. [CrossRef]

37. Salomonsson, D.; Soder, L.; Sannino, A. Protection of Low Voltage DC Microgrids. IEEE Trans. Power Deliv. 2009, 24, 1045-1053. [CrossRef]

38. Brearly, B.J.; Prabu, R.R. A Review on Issues and Approaches for Microgrid Protection. Renew. Sustain. Energy Rev. 2017, 67, 988-997. [CrossRef]

39. Kalage, A.A.; Ghawghawe, N.D. Optimum Coordination of Directional Overcurrent Relays Using Modified Adaptive Teaching Learning Based Optimization Algorithm. Intell. Ind. Syst. 2016, 2, 55-71. [CrossRef]

40. Sahebkar Farkhani, J. Protection Coordination constraints of Distributed Generation in Transient Stability. In Proceedings of the 2019 5th Conference on Knowledge Based Engineering and Innovation (KBEI), Tehran, Iran, 28 February-1 March 2019.

41. Brown, R.E.; Hanson, A.P.; Willis, H.L.; Luedtke, F.A.; Born, M.F. Assessing the reliability of distribution systems. IEEE Comput. Appl. Power 2001, 14, 44-49. [CrossRef]

42. Gonen, T. Electric Power Distribution Engineering, 3rd ed.; Taylor \& Francis Group: Boca Raton, FL, USA, 2015; p. 675.

43. Putra, P.P.; Purba, H.H. Failure Mode and Effect Analysis Power Plant Boiler. J. Optim. Ind. Eng. 2018, 11, 1-5.

(C) 2019 by the authors. Licensee MDPI, Basel, Switzerland. This article is an open access article distributed under the terms and conditions of the Creative Commons Attribution (CC BY) license (http://creativecommons.org/licenses/by/4.0/). 